\title{
Los negocios y la actividad industrial y mercantil en Valladolid vistos por sus protagonistas (1913-27)
}

\author{
Pablo Pérez López *
}

\section{INTRODUCCIÓN}

A partir de la Ley de Bases de 29 de junio de 1911 las Cámaras de Comercio españolas carácter de Cuerpos Consultivos de la Administración, y la inscripción en ellas deviene obligatoria para cuantos comerciantes e industriales paguen un mínimo de contribución. Con el objetivo de fomentar la industria y el comercio, van a desarrollar diversas actividades, entre las que se encuentra la elaboración de una «Memoria sobre el estado de los negocios y el movimiento industrial y mercantil» cada año, que se remite al director general de Comercio, Industria y Trabajo. En el presente estudio analizamos algunos aspectos de las memorias elaboradas por la Cámara Oficial de Comercio e Industria de Valladolid (COCIV), con el fin de acercarnos a la visión que de esas actividades tienen algunos de los hombres más destacados de los que las realizan. La fuente tiene interés tanto por las características generales señaladas más arriba para las Cámaras en general, como -en el caso concreto de Valladolid al menos- por la cualificación de las personas que estarán al frente de esta entidad.

Durante estos años encontramos entre los dirigentes de la entidad vallisoletana a Julio Guillén Sáenz (1867-1950), presidente de 1914 a

* Universidad de Valladolid. 
$1924^{1}$, uno de los fundadores de la Electra Popular Vallisoletana, junto con Santiago Alba, Zorrilla y Muro, entre otros; destacado hombre de negocios, y padre del poeta Jorge Gillén. Con él trabajan como vicepresidentes y actuarán como presidentes en funciones Arturo Illera Serrano (1876-1949) y Vicente Moliner Vaquero (1854-1956) ${ }^{2}$. El primero, doctor en Derecho, se dedicó al negocio familiar de la fabricación de harinas, fue concejal y alcalde de Valladolid, y diputado provincial. Moliner lleva un negocio de comercio familiar y es consejero del Banco Castellano, y de la Cerámica empresas destacadas del ámbito vallisoletano. Fue también alcalde de la ciudad. Finalmente, a partir de 1924 y hasta 1930 encontramos a Alfredo Escribano Rojas (1883-1958) ${ }^{3}$, catedrático y director de la Escuela de Comercio de Valladolid, empresario y consejero de la Sociedad Industrial Castellana, la azucarera más fuerte de estos años, que diversificará progresivamente sus actividades; formó parte además del Consejo de Economía Nacional y de la Junta de Aranceles y Valoraciones.

En las memorias que elaboran abunda la información sobre tráfico de mercancías, producto de las cosechas, estadísticas sobre la matrícula industrial y mercantil, etc., que obviaremos por quedar fuera de nuestros objetivos. Vamos a fijarnos sobre todo en la caracterización general que se hace de la marcha de los negocios, y en los indicadores que pueden ayudar a matizar las afirmaciones generales que se hacen: creación de sociedades anónimas y mercantiles, y situación bancaria; es decir, los indicadores que a nuestro juicio mejor pueden orientarnos acerca de la efectiva modernización económica de Valladolid.

Por lo que respecta a la exactitud de los datos aportados, nos dan hecha la crítica los mismos autores del trabajo: "Difícil es conseguir datos y antecedentes de las entidades y Empresas que explotan servicios públicos y casi imposible la obtención de los que pueden facilitar los particulares, dado el tradicional e injustificado temor de los contribuyentes, que detrás de cada estadística sólo ven una probabilidad en el aumento de los impuestos, y aunque poco a poco hemos ido logrando vencer los obstáculos que se oponían a la realización de los laudables propósitos de esta Cámara, no hemos podido conseguir una información comple-

\footnotetext{
1 Represa Rodriguez, A. y Garabito Gregorio, G., Cámara de Comercio e Industria de Valladolid Cien años de historia, 1886-1986. Valladolid, Cámara de Comercio, 1986, pág 73.

2 Ibidem, págs. 80-81.

${ }^{3} \mathrm{Ibidem}$, pág. 92.
} 
ta (...)» ${ }^{4}$. Esta dificultad, como los autores señalan años más tarde, irá atenuándose, aunque subsisten o aparecen otras como la falta de significación de las variaciones en la matrícula industrial y mercantil por estar más en función de la política fiscal que de la actividad real ${ }^{5}$, o la reticencia de los bancos a facilitar datos pormenorizados sobre su actividad, lo que hará variar el formato informativo que se seguía ${ }^{6}$.

\section{EL PUNTO DE PARTIDA}

El 19 de septiembre de 1914 el director general de Comercio, Industria y Trabajo pedía a las Cámaras información sobre el estado actual y aspiraciones de las industrias y el comercio en sus respectivas provincias. La contestación de Valladolid ${ }^{7}$ nos da una descripción detallada, después de advertir de la forzosa inexactitud de los datos por los motivos ya mencionados, aunque se señala la colaboración de buena parte de las entidades consultadas ${ }^{8}$.

Como industrias peculiares de la provincia se citan las fábricas de harinas, productos cerámicos, metalúrgicos y azúcar. Son las más destacadas y las únicas que tienen un carácter que trasciende el ámbito provincial. Junto a ellas hay que situar, por la importancia de su actividad, a los talleres que la compañía de Caminos de Hierro del Norte tiene en Valladolid. De su funcionamiento da idea el cuadro 1.

Este panorama hace buena la afirmación continuamente reiterada de que la provincia tiene una economía fundamentalmente agrícola ${ }^{9}, y$ no

4 «Memoria sobre el estado de los negocios y movimiento industrial y mercantil durante el año 1913", Boletín de la Cámara Oficil de Comercio e Industria de Valladolid (BCOCIV), núm. 58 (junio de 1914), pág. 2.

${ }^{5}$ Cfr. entre otras «Memoria... de 1923», BCOCIV, núm. 120 (septiembre-octubre de 1924), pág. 5.

${ }^{6}$ Cfr. ibidem, pág. 6

7 “Situación actual de las industrias», BCOCIV, núm. 61, (octubre de 1914), págs. 4-7.

8 «(...) justo es consignar que la mayoría de las entidades a quienes nos hemos dirigido respondieron satisfactoriamente a nuestro requerimiento (...)», Ibidem, pág. 4.

9 "La agricultura, principal y casi exclusiva fuente de riqueza de esta provincia (...)", "Memoria... de 1926", BCOCN, núm. 134, (noviembre de 1926), pág. 10. La fecha es bien significativa. 


\section{CUADRO 1}

Industrias vallisoletanas que venden fuera de la provincia en 1914

\begin{tabular}{|c|c|c|c|c|c|c|}
\hline \multirow{2}{*}{\multicolumn{2}{|c|}{$\begin{array}{l}\text { Valor de las ma- } \\
\text { terias primas em- } 16.460 .000 \\
\text { pleadas }\end{array}$}} & Cerámicas & Yeso & $\begin{array}{l}\text { Metalúr- } \\
\text { gicas }\end{array}$ & Azúcar & $\begin{array}{c}\text { Talleres de } \\
\text { ferrocarril }\end{array}$ \\
\hline & & 125.000 & $?$ & 600.000 & 1.300 .000 & 4.230 .000 \\
\hline $\begin{array}{l}\text { Lugar de proce- } \\
\text { dencia de las } \\
\text { materias primas }\end{array}$ & Castilla & Castilla & Castilla & $\begin{array}{c}\text { Vizcaya } \\
\text { Asturias } \\
\text { Francia } \\
\text { Inglaterra } \\
\text { Alemania }\end{array}$ & Castilla & $\begin{array}{l}\text { España } \\
\text { Francia } \\
\text { Inglaterra } \\
\text { Alemania }\end{array}$ \\
\hline $\begin{array}{l}\text { Obreros que em- } \\
\text { plean }\end{array}$ & 4.000 & 200 & 100 & 700 & $?$ & 1.568 \\
\hline $\begin{array}{l}\text { Valor del producto } \\
\text { vendido fuera de } \\
\text { Valladolid }\end{array}$ & 17.600 .000 & 150.000 & 150.000 & 13.110 .000 & $?$ & $?$ \\
\hline $\begin{array}{l}\text { Destino de las } \\
\text { ventas }\end{array}$ & $\mathrm{Ca}$ & astilla, Astur & rias, Gali & cia, Andaluc & sía, Levant & \\
\hline $\begin{array}{l}\text { Recargo que su- } \\
\text { pone el transporte } \\
\text { en el precio del } \\
\text { producto }\end{array}$ & $6 \%$ & $100-150 \%$ & $300 \%$ & $?$ & $?$ & \\
\hline
\end{tabular}

es extraño que al hablar de industrias de fácil implantación se mencionen las de transformación de productos del campo como fábricas de sémola, almidón o conservas de verduras.

Entre las dificultades para el desarrollo industrial que se señalan como más graves están las relativas al transporte, que supone fuertes recargos sobre el precio de fábrica en los productos que se exportan; en ello se cifra la dificultad para conquistar nuevos mercados. Al extrajero Valladolid solamente exporta piñones, pieles y lanas, y no parece haber perspectivas de mejora inmediatas si no es mediante la ampliación de la infraestructura de transportes, como por ejemplo si se dotara a la capital 
castellana de un ferrocarril directo a Vigo, que facilitaría la salida de los productos a ultramar.

La segunda dificultad citada - aparecida con la guerra europea- es la restricción del crédito por parte del Banco de España y las dificultades para la negociación de giros y descuentos que se ha derivado del conflicto. Frente a esta situación aparece una reivindicación que veremos será característica de todos los informes emitidos por la COCIV: reducción de tipos de interés y de descuento, concesión de créditos personales más fácilmente y admisión de valores industriales en garantías de préstamos y créditos. Junto a esto, se solicita también un mayor apoyo financiero a las actividades agrícolas - a través del Banco Hipotecario-, de forma que se favorezca la adquisición de semillas, y el aumento de las superficies roturadas. En este sentido es forzoso recordar el impacto que sobre la agricultura de estas tierras había tenido la plaga filoxérica en los primeros años del siglo, que había dejado a algunas comarcas antes prósperas - como la de Nava del Rey- en un estado de postración del que tardarían en salir ${ }^{10}$.

Esta última reclamación se acentúa con fuerza haciendo notar que al ser la producción agrícola la base de la economía de la provincia, su marcha repercute en la industria de forma decisiva, tanto, que al hablar de la marcha de los negocios encontraremos como primera referencia la calidad de las cosechas.

\section{LA MARCHA DE LOS NEGOCIOS}

Abriendo la Memoria de 1914 encontramos una afirmación que pone en antecedentes de todo lo que más adelante se irá detallando: "La nota dominante del estado general de los negocios en toda la provincia de Valladolid es la paralización" "'. Las causas, el retraimiento de los capitales por la «inseguridad" y la "persistente crisis agrícola». La novedad más importante, la constitución de Sociedades cooperativas de consumo - promovidas por los sindicatos católicos en los pueblos- que están provocando el cierre de numerosas tiendas.

Este tono de queja va a ser constante en todas las memorias de estos años: no hay ni siquiera uno en el que no se use la palabra crisis

${ }^{10}$ Cfr. BCOCIV, núm. 58 , junio de 1914 , pág. 3.

11 Ibidem, pág. 2. 
para referirse a la situación industrial y comercial por un motivo $u$ otro. Lo que sí variarán son las razones que se aleguen como causantes de esas situaciones críticas. De 1913 a 1917 será la guerra europea con el consiguiente «ambiente de inseguridad y temor que aleja a los capitales de la producción y paraliza toda clase de iniciativas" ${ }^{12}$, además de las dificultades de abastecimiento de materias primas y de combustibles, por la misma razón. A esto se añaden las dificultades de transporte, que serán una constante como ya adelantamos en el apartado anterior ${ }^{13}$.

En los años dieciocho a veinte un nuevo factor va a ser destacado como causante de graves trastornos: la cuestión social. «(...) la normalidad de la vida tardará aún bastante tiempo en restablecerse, puesto que rápidamente han surgido [terminada la guerra] importantes problemas en todos los órdenes y especialmente la llamada cuestión social, que se presenta en forma tal de violencia que hace temer hondas perturbaciones si no se llega pronto a su definitiva resolución» ${ }^{14}$. Esa nueva violencia se entenderá como una de las causas del encarecimiento de la vida y del retroceso en la marcha de los negocios ${ }^{15}$. La actitud ante este problema -que se explica como un problema de subsistencias- será marcadamente paternalista, y las medidas para paliarlo que se citan son el esfuerzo de las autoridades locales y personas pudientes para rebajar los precios del pan, y recursos allegados mediante suscripciones y "sacrificios que voluntariamente se impusieron tanto los fabricantes como los vendedores" ${ }^{16}$. Junto a esto, otra causa generadora de problemas en la inmediata postguerra sería la desatinada actuación de las autoridades: «(..) la equivocada política de abastos que ha venido siguiéndose, y la actuación verdaderamente errónea, de las Juntas y Comisiones de Subsistencias, han empeorado la situación, dando lugar a la carestía y escasez de algunos productos" ${ }^{17}$.

En la década de los veinte, las trabas que se señalan podrían resumirse en la fiebre especulativa que aparece en 1920, la falta de disponibilidad de numerario como consecuencia del mucho que absorbe la

12 «Memoria... de 1914», BCOCIV, núm. 69, [junio de 1915], pág. 2.

${ }^{13}$ «La falta de combustible y la escasez de primeras materias han determinado la paralización temporal en algunas industrias; las medidas restrictivas adoptadas por el Comité de Transportes Terrestres para regularizar el tráfico ferroviario han impedido en unos casos la salida de productos, y en otros la recepción de artículos indispensables para el consumo", «Memoria... de 1917», BCOCIV, núm. 94, [septiembre de 1918], pág. 5.

${ }^{14}$ «Memoria... de 1918", BCOCIV, núm. 97, [octubre de 1919], pág. 5.

${ }^{15}$ Cfr. «Memoria... de 1919", BCOCIV, núm. 104, [noviembre de 1920].

16 «Memoria... de 1920», BCOCIV, núm. 108, [octubre de 1921], pág. 2.

${ }_{17}$ "Memoria... de 1919", BCOCIV, núm. 104, [noviembre de 1920], pág. 8. 
campaña de Marruecos, la política restrictiva seguida por los bancos en la concesión de créditos, y los apremios con que la Hacienda atosiga a los negociantes. Por supuesto, como telón de fondo seguimos encontrando la calidad de las cosechas, si bien los años en que son buenas, no solucionan los problemas, solamente los transforman: de tener la carestía de los productos como obstáculos, se pasa a la baja de los precios como factor paralizador. Por último, y como dato significativo del grado de modernización de la provincia, en los años 1923 a 25 se informa de la paralización de las fábricas de harinas en el verano a causa del estiaje de los ríos y canales.

Así pues, nos encontramos ante una economía que depende en buena medida del clima, de los abastecimientos y de la iniciativa ajena 0 estatal, en la que la actividad empresarial es reducida y poco dinámica salvo contadas excepciones. No es extraño por tanto que la preocupación por un arancel proteccionista capitalizara los anhelos de las élites del momento ${ }^{18}$.

\section{SOCIEDADES ANÓNIMAS Y MERCANTILES}

La creación de sociedades se ha considerado un índice de dinamismo empresarial, señalando cómo en la región castellana Valladolid iría a la cabeza frente al casi nulo movimiento en otras provincias de la región ${ }^{19}$. Por lo que se refiere a las anónimas el balance de estos años sería el que reflejamos en el cuadro 2. Por su parte, las sociedades mercantiles manifiestan una tendencia a la baja que queda patente en el cuadro 3.

Es claro que este movimiento no resume toda la actividad empresarial. Hay que tener en cuenta que las sociedades más fuertes, gestionadas por los empresarios más innovadores habían sido fundadas con anterioridad a esta fechas: la Sociedad Industrial Castellana (azucarera con un capital de 12 millones de pesetas en 1900), Colonia Agrícola Industrial del Duero (otra azucarera con 3 millones en 1900), Banco Castellano, Electra Popular Vallisoletana (2,5 millones en 1906), y la Cerá-

${ }^{18} \mathrm{El}$ arancel de 1921 se considera insuficiente. Cfr. «Memoria... de 1921», BCOCIV, núm. 113, [diciembre de 1922], pág. 2.

19 VV. AA., Historia de Castilla y León. 10. Tiempo de reto y esperanza (Siglo xx). Valladolid, Ámbito, 1986, págs. 80-82. 
mica (amplió su capital a 4 millones en 1923), etc. ${ }^{20}$. Esta comparación permite concluir que el ya pequeño movimiento industrial vallisoletano, en

CUADRO 2

Creación de sociedades anónimas

\begin{tabular}{|c|c|c|c|}
\hline Año & Sede & Actividad & $\begin{array}{l}\text { Capital } \\
\text { (en miles } \\
\text { de ptas.) }\end{array}$ \\
\hline 1913 & Valladolid & Espectáculos & 25 \\
\hline 1913 & Nava del Rey & Producción de electricidad & 100 \\
\hline 1914 & Valladolid & Espectáculos taurinos & 3 \\
\hline 1914 & Valladolid & Contrat. Obras y Serv. Municipales & 10 \\
\hline 1915 & Valladolid & Teatro & 3 \\
\hline 1915 & Valladolid & Teatro & 10,5 \\
\hline 1915 & Valladolid & Espectáculos taurinos & 3 \\
\hline 1916 & Valladolid & Alquiler de contadores & 250 \\
\hline 1916 & Valladolid & Fabricación de gaseosas & 10 \\
\hline 1917 & Valladolid & «Importación y ventas» & 500 \\
\hline 1918 & Valladolid & Fabricac. de colas, gelatinas y abonos & 275 \\
\hline 1918 & Valladolid & Venta de cerámica & 20 \\
\hline 1920 & Castronuño & Producción de electricidad & 150 \\
\hline 1924 & Valladolid & Productos químicos & 700 \\
\hline 1924 & Valladolid & Antracitas & 500 \\
\hline 1925 & Valladolid & Fabricación de carburadores & 750 \\
\hline 1926 & Valladolid & Periódico diario & 50 \\
\hline 1927 & Valladolid & Fabricación de harinas & $?$ \\
\hline 1928 & Valladolid & Venta de confecciones & $?$ \\
\hline
\end{tabular}

${ }^{20}$ Cfr. Ibidem. 
CUADRO 3

Movimiento de sociedades mercantiles

\begin{tabular}{cccc}
\hline Año & Creadas & Disueltas & Balance \\
\hline 1913 & 6 & 6 & 0 \\
\hline 1914 & 9 & 8 & +1 \\
\hline 1915 & 9 & 5 & +4 \\
\hline 1916 & 12 & 14 & +2 \\
\hline 1917 & 3 & 4 & -1 \\
\hline 1918 & 16 & 14 & +2 \\
\hline 1919 & 36 & 19 & +17 \\
\hline 1920 & 12 & 23 & -11 \\
\hline 1921 & 8 & 20 & -12 \\
\hline 1923 & 4 & 5 & -1 \\
\hline 1926 & 18 & 19 & -1 \\
\hline
\end{tabular}

estos años experimenta una relentización que justificaría las continuas referencias a la crisis que hemos mencionado.

\section{SITUACIÓN BANCARIA}

Hasta 1922 sólo operan en Valladolid dos bancos, el de España y el Castellano, a los que se suma en 1922 el Hispano Americano. A partir de las memorias de esas entidades, la COCIV elabora anualmente unos resúmenes de la situación bancaria que constituyen un indicador complementario apreciable.

La nota más destacada en este aspecto la tenemos en el continuo aumento de la cuantía de los valores depositados en los bancos, más aún si tenemos en cuenta la advertencia que se hace en 1914: "Los efectos en depósito constituídos en los bancos ascendían, en fin de diciembre a cerca de 109.000 .000 de pesetas. Este dato es altamente 
desconsolador y demuestra el alejamiento de capital de las explotaciones industriales y mercantiles, pues no habiéndose constituído en esta provincia ninguna nueva sociedad anónima ni habiendo emitido nuevas obligaciones las ya existentes, es lógico suponer que los nueve millones que han aumentado los depósitos han sido, si no en su totalidad, en su mayor parte en títulos de la deuda pública, cuyos tenedores prefieren la mayor comodidad y seguridad en la inversión de sus fondos al empleo de ellos en empresas que tienden a favorecer el desarrollo de la producción nacional» ${ }^{21}$. Esta tendencia a la comodidad y seguridad como se observa en la gráfica 1 continuó en los años siguientes sin que encontremos un alto en el crecimiento de los valores de los depósitos hasta 1926.

A esta actitud temerosa de los particulares se va a sumar la de los bancos reflejada en la restricción del crédito que se observa en las gráficas 2 y 3 . Ya en los años veinte, el crédito volverá a aumentar apoyado sobre todo en las garantías de valores, mientras que los de garantía personal continúan su tendencia a la baja (cfr. gráficas 4 y 5).

Por to que se refiere a existencias en metálico y movimiento de numerario, en contraste con la reiterada afirmación de la situación de estancamiento para los negocios encontramos un aumento progresivo en

Gráfica 1. Valor de los efectos depositados en los bancos (1913-27)

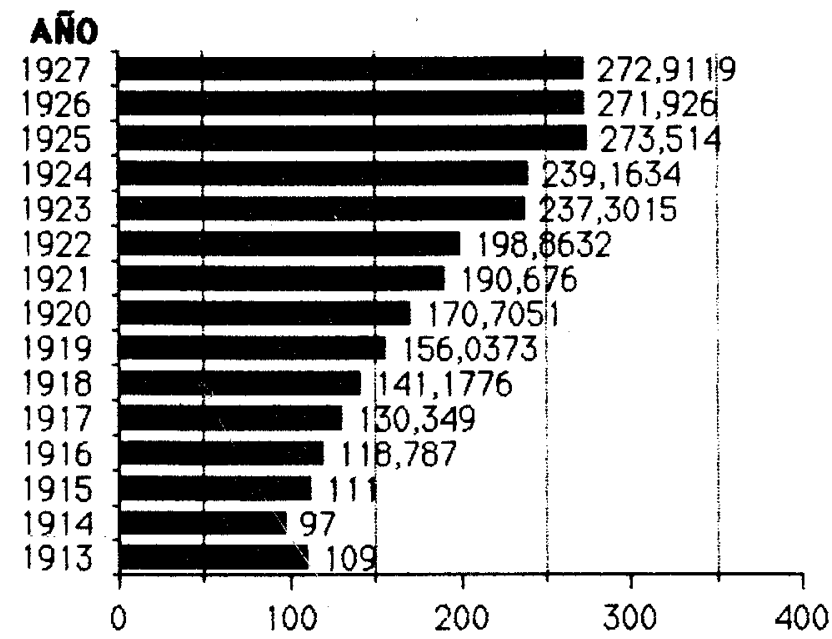

CUANTÍA DE LOS DEPOSITOS (EN MILLONES DE PTAS.)

21 «Memoria... de 1913", BCOCIV, n. ${ }^{\circ}$ 58, (junio de 1914), pág. 4. 
Gráfica 2. Incremento del movimiento de las cuentas de crédito con garantía personal en la sucursal del Banco de España en Valladolid con respecto al registrado en 1913 (1915-22)

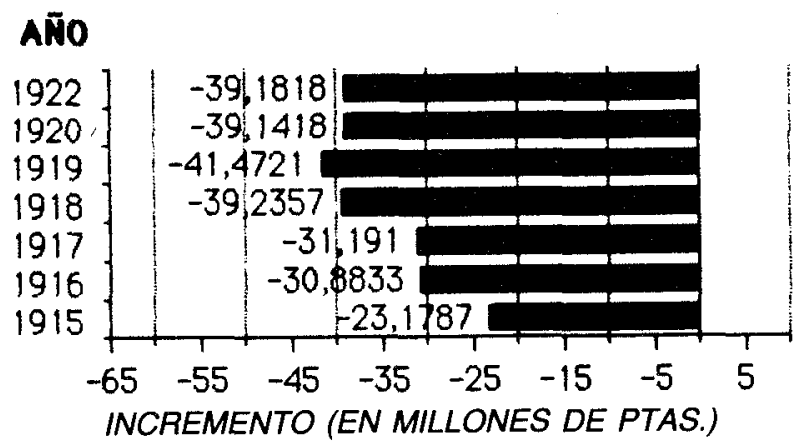

Gráfica 3. Incremento del movimiento de las cuentas de crédito con garantía de valores con respecto al que tuvieron en 1914 (1915-22)

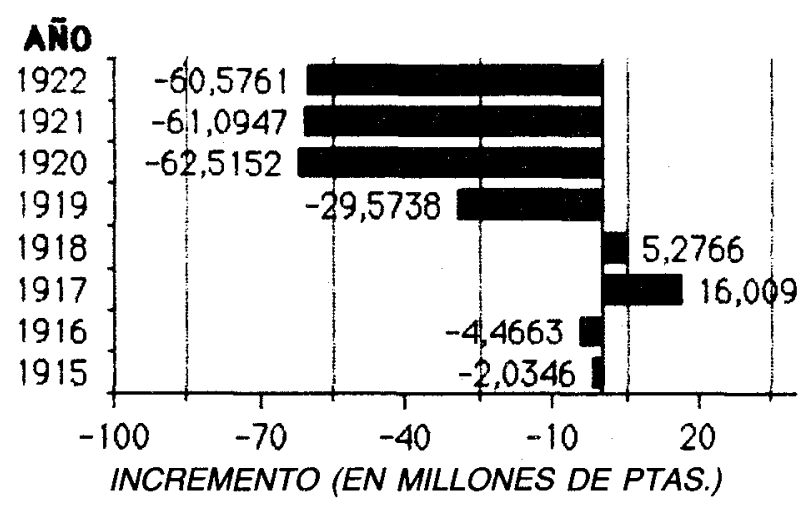

Gráfica 4. Créditos concedidos (1923-27)

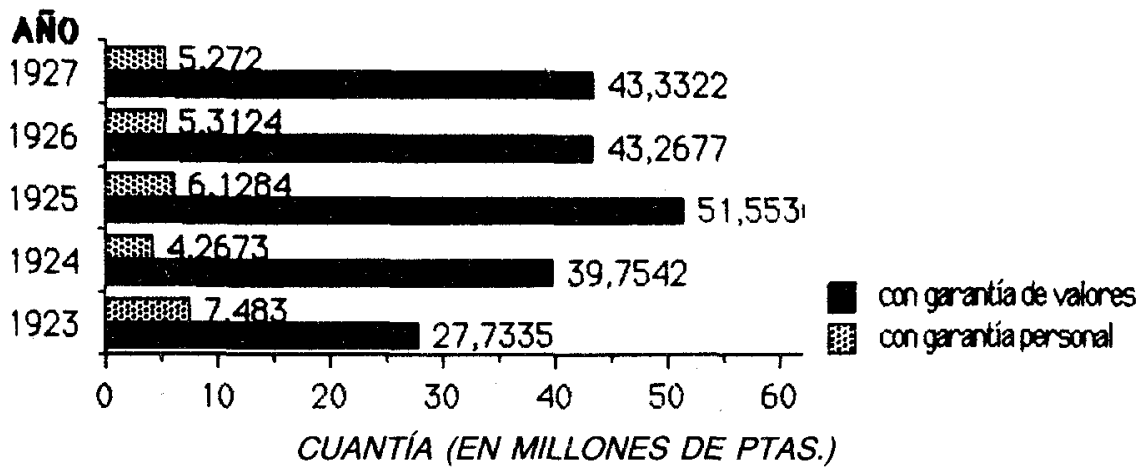


Gráfica 5. Promedio de las $\mathrm{C} / \mathrm{C}$ sin interés (1913-18)

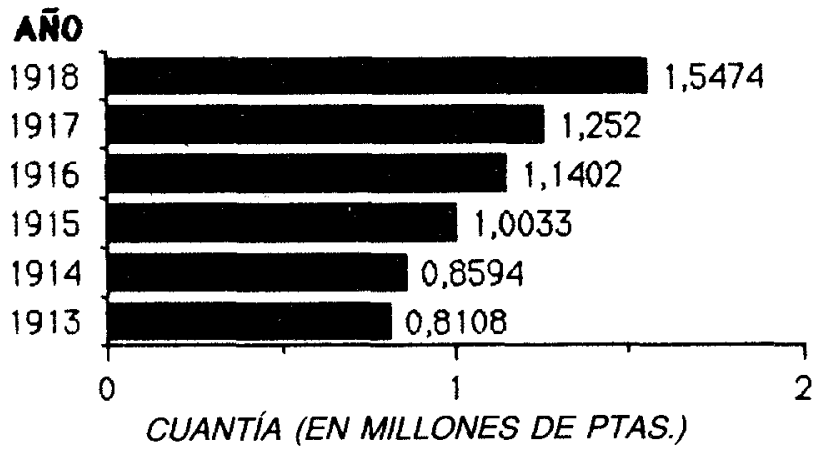

Gráfica 6. Saldo de las $\mathrm{C} / \mathrm{C}$ con interés (1913-22)

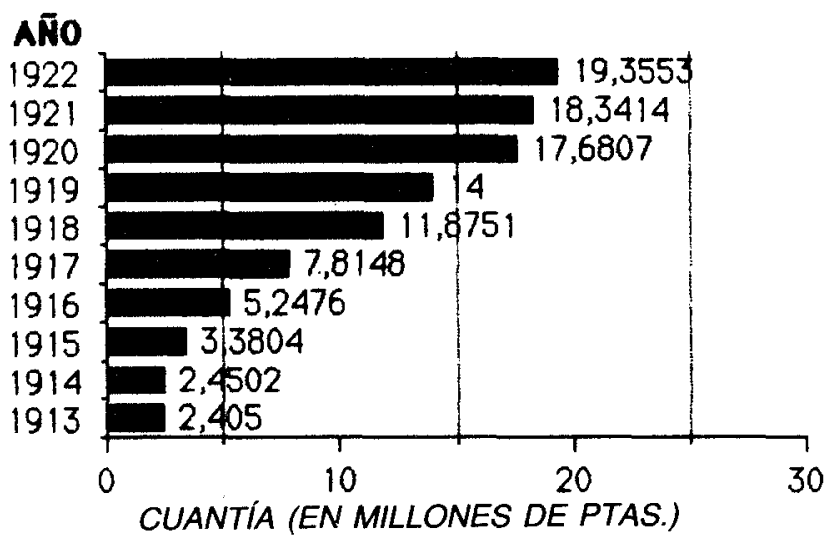

los saldos como se aprecia en las gráficas 5,6 y 7 . Hay que tener en cuenta además que desde 1917 el Banco Castellano crea una Caja de Ahorros en la que las cuentas pasan de un saldo de dos millones a 31 de diciembre de 1917, a más de veintiséis al final de 1921. Por tanto, no parece que quepa atribuir a la falta de dinero la escasísima inversión sino más bien al ya mencionado retraimiento de los posibles inversores.

Finalmente, los datos sobre las cuantías de los efectos descontados (gráficos 8, 9 y 10) confirman el retroceso de las negociaciones de 1913 a 1921, y una progresiva recuperación desde 1923. No obstante, la consideración de que el valor de los efectos descontados en Valladolid sea en 1920 menor que en 1914 de buena idea del estancamiento que se da en estos años. 
Gráfica 7. Saldo de las C/C (1923-27)

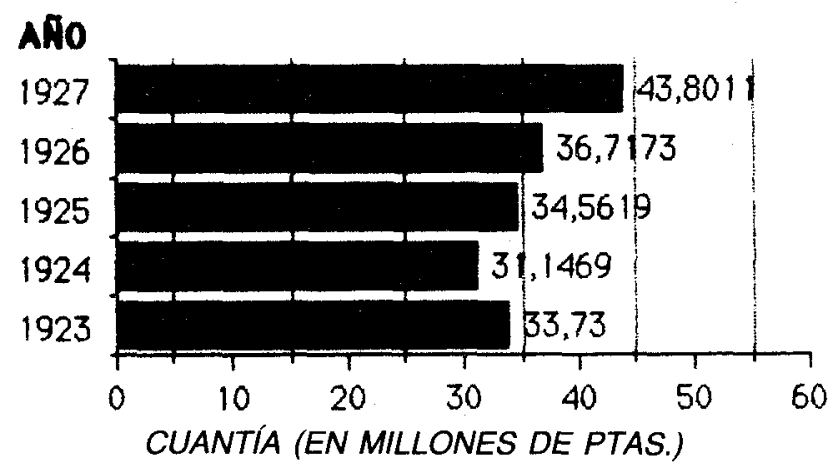

Gráfica 8. Valor de los efectos descontados por los bancos de Valladolid en la plaza (1914-20)

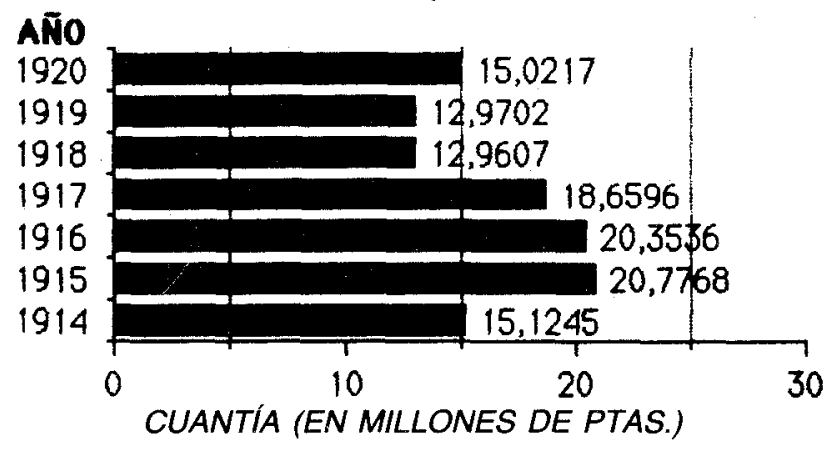

Gráfica 9. Incremento del valor de los efectos descontados por los bancos de Valladolid sobre los pueblos de la provincia y otras plazas (1915-21)

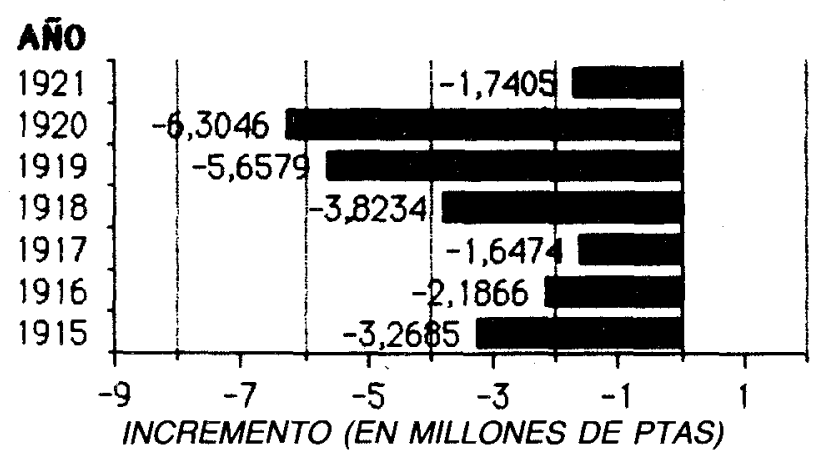


Gráfica 10. Valor de los efectos descontados por los bancos de Valladolid (total, 1923-27)

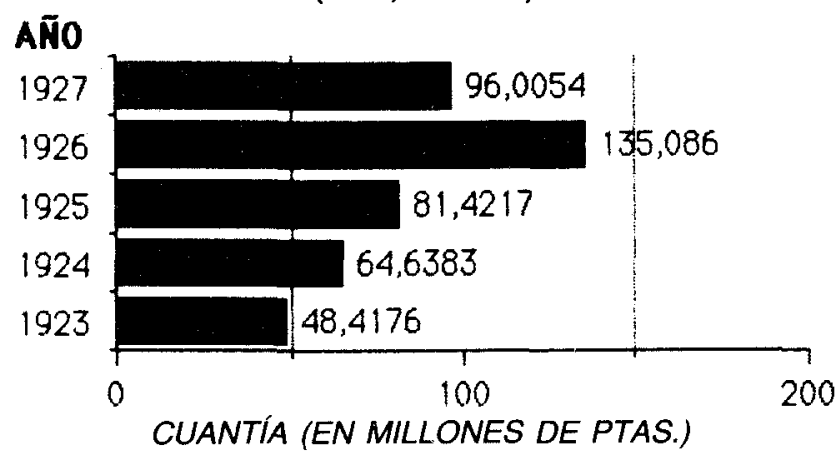

\section{CONCLUSIONES}

Nos enfrentamos a los datos anteriormente expuestos con el afán de detectar rasgos de modernización en la vida económica vallisoletana y parece que lo primero que hay que concluir es que los indicadores de modernización en esta etapa concreta son muy escasos si no inexistentes. La impresión que causa todo lo revisado es la de encontrarnos ante una «modernización frustrada». Los hombres que habían impulsado la industrialización y la dinamización del comercio a fines del xIX y principios del $x x$ se encuentran desde 1913 paralizados por dificultades que no saben o no pueden salvar. La economía sigue teniendo un tono predominántemente agrícola y las industrias montadas en torno al negocio de granos o la remolacha permanecen atentas a la protección que el Estado pueda prestarles - la obsesión proteccionista - sin que haya apenas afanes inversionistas o diversificación de los negocios que permita hablar de asunción de riesgos empresariales. Al contrario, y como ya se ha señalado, hay una "comodidad" entre los vallisoletanos que les aleja de aventuras económicas, y que parece ser la principal causante del pesimismo que se observa como característica en los dirigentes de la Cámara; un pesimismo que quizá tuviera efectos paralizadores todavía más intensos que el retraimiento de posibles nuevos inversores, la agitación social o la guerra europea.

No podemos hablar de recesión económica pero sí de paralización o estancamiento, y para salir de ese estado habría hecho falta algo más que reclamar el auxilio de Madrid. Expresiones como "Nadie más que 
el Banco de España puede acudir a remediar la crisis económica” ${ }^{22}$, «(...) vea [el Director General] la manera de que el Banco Hipotecario conceda préstamos (...) ya que el establecimiento de Bancos agricolas no es labor que se realice en poco tiempo" ${ }^{23}$, o "La implantación del nuevo Arancel, eminentemente proteccionista, no tuvo la eficacia necesaria (...) ${ }^{24}$, son bastante expresivas y dicen poco a favor de la capacidad de reacción e innovación de las élites vallisoletanas. Si los hechos desmintieran esta apreciación, podría pensarse en una lógica actitud pedigüeña al dirigirse a un alto funcionario de Fomento, pero no nos parece que sea el caso.

Quizá en esta etapa se encuentre una de las claves del atraso económico castellano, y del enfrentamiento con Cataluña que se irá haciendo más agudo hasta estallar en las protestas contra el Estatuto de la II República. En el fondo parece encontrarse la idea de que el avance económico es fruto sobre todo del apoyo que el Estado preste, y en ese caso, todas las diferencias regionales que van apareciendo se reducirían a un agravio comparativo.

22 "Situación actual de las industrias», BCOCIV, n. ${ }^{\circ} 61$, (octubre de 1914), pág. 6.

${ }^{23}$ Ibidem.

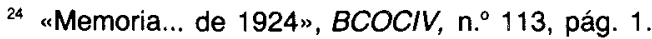

